\title{
The future of small bowel transplantation
}

\author{
Deirdre A Kelly, John A C Buckels
}

Although transplantation of solid organs such as kidney and liver have been established since the 1970s and 1980 s, the future of small bowel transplantation as treatment for intestinal failure is only just evolving. Early clinical experience was almost universally unsuccessful but recent developments in surgical technique, immunosuppression, and postoperative management have improved outcome with a $50 \%$ survival in at least 100 operations. $^{1}$

Small intestinal transplantation was first demonstrated to be technically feasible in animals in $1902,2-4$ and in humans in the 1980 s, $^{5-7}$ but it was not until the Pittsburg group initiated a programme of small bowel transplantation using the novel immunosuppressant agent FK506 ${ }^{8-12}$ that significant progress was made.

\section{Intestinal failure}

Intestinal failure is defined as the inability of the small intestine to absorb sufficient solute to maintain nutrition and/or positive fluid and electrolyte balance. ${ }^{13}$ It is more common in children, and the main causes are congenital abnormalities of the intestine and the short gut syndrome secondary to neonatal surgery for a number of conditions (table).

Current treatment for intestinal failure is total parenteral nutrition (TPN) and many patients may be successfully maintained in this way by specialist units. ${ }^{14-16}$ Although successful provision of TPN at home has greatly improved the outcome and quality of life for children with short bowel syndrome, morbidity remains significant ${ }^{17-19}$ and the financial cost high. ${ }^{20}$ There are many complications which include cholestasis, cholelithiasis, pulmonary embolism, loss of vascular access, and recurrent catheter sepsis. ${ }^{21-23}$

Death in childhood is related to the development of liver dysfunction, as more than $40 \%$ of patients with complete intestinal failure will develop severe liver disease within two years. ${ }^{22}$

\section{Liver Unit, \\ Children's Hospital, \\ Ladywood Middleway, \\ Birmingham B16 8ET \\ D A Kelly}

Department of Surgery, Queen Elizabeth Hospital,

Birmingham

J A C Buckels

Correspondence to: Dr Kelly.

\section{Indications for small bowel}

\section{transplantation}

Small bowel transplantation should be considered for all children with irreversible intestinal failure who are dependent on parenteral nutrition for survival and in whom all attempts to improve intestinal adaptation have been unsuccessful. Potential candidates may require small bowel transplantation alone or combined with a liver transplant.

The current indications for isolated small bowel transplantation include: (1) loss of vascular access with normal liver function and histology and (2) intractable gastrointestinal fluid loss. The current indications for combined small bowel/liver transplantation are: (1) irreversible liver disease secondary to TPN; (2) loss of vascular access with evidence of significant liver disease; and (3) inborn errors of liver metabolism leading to small bowel failure (for example, protein C, S deficiency).$^{24} 25$

At the moment it is hard to justify small bowel transplantation in those patients who are successfully managed on TPN, although it is possible that in the future social, psychological, and cost pressures may increase the indications for transplantation. The contraindications include uncontrolled sepsis or malignancy elsewhere in the body, HIV infection and severe cerebral, cardiac, or respiratory disease. Congenital immunodeficiency may be a particular contraindication because of the development of severe graft versus host disease (GVHD) from donor lymphocytes contained within the intestinal graft. ${ }^{26}$ Currently there are no age or size limitations, although in practice donor availability may preclude intestinal transplantation in very small infants.

\section{Patient selection and preparation \\ TIMING}

As quality of life may be acceptable for many children maintained on parenteral nutrition the timing of this operation may be difficult. Furthermore, the difficulty in obtaining suitable age and size matched donors for very small children means a lengthy wait for a suitable organ. In Pittsburg 37\% of patients died while awaiting small bowel transplantation. ${ }^{9}$

We have recently evaluated 17 children (aged 4 months to 13 years) for small bowel transplantation. Ten children were referred with liver disease and seven with loss of venous access. In this group of children 11 died preoperatively (seven were too ill to place on the 
transplant list and four died waiting for a donor. The children with the highest plasma bilirubin concentration at the time of evaluation had the shortest duration of survival. ${ }^{27}$ Thus it is important to refer children for small bowel transplantation as soon as hepatic dysfunction becomes apparent or there are difficulties with vascular access in order to allow sufficient time for assessment and obtaining a donor.

\section{Assessment}

The assessment for small bowel transplantation focuses on establishing: (1) hepatic and intestinal function; (2) patent vessels; and (3) physical and psychological preparation of child and family.

\section{GASTROINTESTINAL FUNCTION}

It is necessary to establish that intestinal failure is irreversible. The precise anatomy, motility, and function of the remaining gastrointestinal tract should be assessed. Gastric emptying studies and upper and lower gastrointestinal endoscopy including histology of the bowel should be performed. The capacity of the peritoneal cavity should be measured as this may be a limiting factor in donor selection.

\section{HEPATIC FUNCTION}

It is important to assess the extent of fibrosis/cirrhosis and portal hypertension, especially in patients without overt liver disease.

For technical reasons the vascular supply to the liver needs to be determined by ultrasonic radiology. The presence or absence of gall stones and common bile duct stones should be established by ultrasound or endoscopic retrograde cholangiopancreatography.

\section{VASCULAR ACCESS}

The presence of patent vessels and vascular thrombosis is usually established using Doppler ultrasound, although angiography may be required.

GENERAL ASSESSMENT

Anthropometry to measure nutritional status and careful cardiac and pulmonary assessment to establish incidence of pulmonary embolism from central venous lines ${ }^{23}$ is essential.

\section{PSYCHOLOGICAL ASSESSMENT}

As small bowel transplantation remains a new procedure in the UK it is important that the family are honestly appraised of the risks and complications of this procedure in order to make an informed decision. The psychological preparation of the child is paramount and should include preparation for a stoma and ileostomy.

On completion of the assessment, the decision will be made whether the child requires an isolated small bowel transplantation or combined liver and small bowel transplantation. Current experience suggests that combined liver and small bowel transplantation may reduce the chances of intestinal rejection postoperatively. ${ }^{7}$ It is possible that patients with early liver disease may have progression of TPN cholestasis postoperatively particularly if there are problems with establishing intestinal function ${ }^{28}$ and thus the liver should be replaced if significantly affected.

It is important to ensure that complications related to either liver or intestinal failure are medically managed and sepsis is effectively treated. It is our practice to start selective bowel decontamination (polymyxin B, gentamicin, and amphotericin administered orally) once children are placed on the waiting list.

\section{Donor procurement and operative technique}

Donor procurement and operative technique are now well established. ${ }^{29} 30$

Grafts must be ABO blood group compatible and preferably matched for cytomegalovirus status. Selection of donor size is of critical importance as previous surgery in the recipient often leads to extensive adhesions and contraction of the peritoneal cavity so that the ideal donor should weigh approximately $20 \%$ less than the recipient. For isolated small bowel transplantation the entire small bowel together with the right colon is removed with its vascular pedicle comprising the superior mesenteric artery and origin of the portal vein (fig 1). Recent experience has demonstrated advantages in including the right colon with the small bowel in terms of fluid and short chain fatty acid absorption. In combined grafts the same bowel is removed but the portal vein is left in continuity with the liver (fig 2). In both situations the organs are perfused with University of Wisconsin Solution which will allow preservation for up to 10 hours.

In isolated small bowel grafts the superior mesenteric artery is anastomosed to the aorta, usually via a conduit of donor iliac artery, and venous drainage established by anastomosing the donor portal vein to the side of the recipient portal vein. The upper end of the graft is

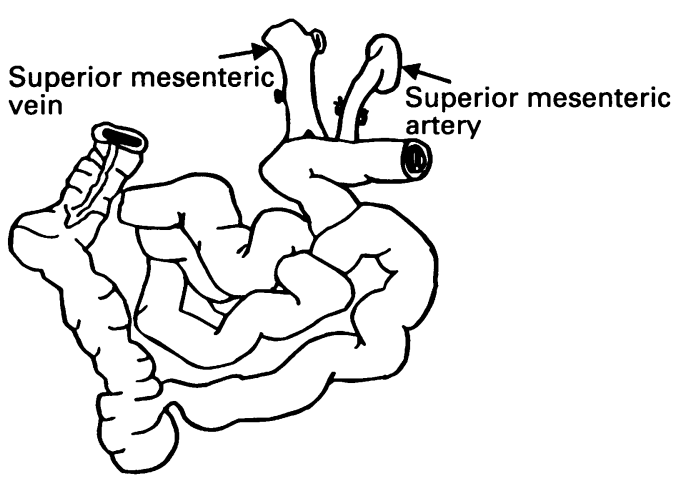

Figure 1 Isolated small bowel transplantation. The donor isolated small bowel is removed with the right colon. The superior mesenteric artery is anastomosed to the recipient aorta and the superior mesenteric vein anastomosed to the side of the recipient portal vein. 




Figure 2 Combined small bowel and liver transplantation. The donor liver is removed with the small bowel and right colon. The venae cavae above and below the liver are anastomosed to the recipient cavae; vascular inflow is provided by anastomosing the common hepatic and superior mesenteric arteries to the aorta using an interposition iliac graft. For clarity the common bile duct has been omittedthis is anastomosed to the recipient bile duct if suitable, or to a Roux-en-Y loop of either host or donor jejunum.

anastomosed to the duodenojejunal flexure. The management of the distal intestine varies with individual cases. The transplanted right colon is anastomosed if possible to the distal colon in the recipient but a distal ileostomy is established proximal to this in all cases to facilitate monitoring of graft function including enteroscopy to detect rejection. This is closed approximately six months later.

For combined small bowel liver grafts the presence of cirrhosis with portal hypertension can lead to significant bleeding and great care is taken to obtain haemostasis. The liver and small bowel are implanted as a monobloc in the orthotopic position. The caval anastomoses above and below the liver are performed first. If the recipient cava has been retained, a single anastomosis between the donor cava and recipient hepatic veins (piggy back technique) may be used. The whole graft is then revascularised by anastomosing both the hepatic artery and superior mesenteric artery together on a patch to the recipient aorta. In this situation the main portal flow to the liver comes via the grafted small bowel, though the recipient portal vein draining spleen, pancreas, stomach, and any residual intestine will need to be anastomosed to the side of the donor portal vein. The bile duct is anastomosed to either the recipient bile duct or to a Roux-en-Y loop. In both situations a feeding jejunostomy is performed so that early postoperative enteral feeding may be given.

\section{Postoperative management}

The key to successful postoperative management is effective teamwork between anaesthetists, surgeons, paediatricians, nursing and paramedical staff. Patients receiving combined liver and small bowel transplantation are likely to spend longer in both the intensive care unit and in hospital than those receiving isolated small bowel transplantation alone. ${ }^{31}$ The main issues in postoperative management are as follows:
(1) IMMUNOSUPPRESSION AND REJECTION

Donor lymphocytes, mesenteric lymph nodes and Peyer's patches are transplanted with the small bowel graft which are replaced in time by recipient lymphocytes leading to either GVHD or rejection. ${ }^{32}$

Although animal studies suggested that GVHD would be a major problem after small bowel transplantation, in practice it has not been a significant problem in humans except in immunodeficient patients. ${ }^{26} 32$

Although combined liver/intestinal transplantation has been performed successfully using cyclosporin and steroids, ${ }^{73}$ it is clear that the frequency and severity of both hepatic and intestinal rejection is much reduced using FK506, even in recipients of isolated small bowel transplantation. ${ }^{34} 35$

Intestinal rejection may occur from the seventh postoperative day. The clinical symptoms include fever, malaise, abdominal pain, nausea, and an increase in stoma output. Occasionally acute rejection may present with septic shock due to bacterial translocation. Confirmation of rejection may be obtained by visualisation of the stoma, or by ileoscopy or endoscopic visualisation of the jejunum. The intestinal mucosa and stoma may look oedematous, friable, or ulcerated but both clinical manifestations and endoscopic appearances may be normal in early rejection. Rejection may be patchy and multiple endoscopic biopsies are therefore necessary. The histological signs of rejection which occur include an inflammatory infiltrate with lymphoblasts, eosinophils and macrophages, epithelial necrosis with crypt cell damage and apoptosis and ulceration and mucosal sloughing. The early diagnosis of acute rejection is unsatisfactory despite attempts to use immunohistochemistry to identify pericryptic CD3 + cells and the appearance of HLA-DR antigens. ${ }^{36}$ Improved diagnosis of rejection would be a significant advance for the future.

Continued acute rejection may lead to chronic changes with villous blunting and fibrosis of the lamina propria. Rejection occurs in $66 \%$ of patients after intestinal transplantation and is normally treated by increasing immunosuppression either with a pulse dose of methylprednisolone or increasing FK506. As rejection is likely to be associated with bacterial translocation it is usual to treat with intravenous antibiotics and bowel decontamination until the rejection episode has resolved.

Chronic rejection leads to an obliterative vasculitis leading to ischaemia and fibrosis of the intestine and its mesentery. It is not normally diagnosed until the graft has been removed and may result in late graft loss.

\section{(2) INFECTION}

Over $90 \%$ of children in Pittsburg experienced bacterial, viral, or fungal infection despite adequate prophylaxis. ${ }^{37}$ Viral infections, especially cytomegalovirus and Epstein-Barr virus are a particular problem as most children are negative for these viruses before transplant and selection of potential donors for their 
cytomegalovirus and Epstein-Barr virus status is impractical.

Eleven per cent of children who were negative for Epstein-Barr virus on FK506 developed lymphoproliferative disease, half of whom developed lymphoma. ${ }^{38}$ The high incidence of lymphoproliferative disease in children on FK506 39 is particularly worrying and raises important issues about long term outcome and survival in this vulnerable group of children. ${ }^{38}$

\section{(3) INTESTINAL FUNCTION}

The transplanted intestine undergoes a number of physiological readjustments before intestinal function resumes. There is permanent disruption of the extrinsic autonomic nervous system but only temporary loss of lymphatic drainage. Mucosal damage secondary to ischaemia or handling of the donor graft recovers within $2-5$ days as does intestinal motility. ${ }^{40}$ Animal studies indicate that monosaccharides and disaccharides are equally well absorbed and are sensitive markers of the return of intestinal function. ${ }^{40}$

Early enteral feeding with a whole protein feed is desirable as both animal and human studies suggest that this is associated with less bacterial translocation and improvement in mucosal atrophy. ${ }^{41} 42$ Carbohydrates are introduced as glucose polymer and the energy density is increased with sucrose and lactose as function improves. ${ }^{43}$ Fat should be introduced as medium chain triglycerides until lymphatic drainage has been re-established, which may take several months. 4043

Motility disturbances secondary to disruption in the enteric nervous system may result in delayed gastric emptying or diarrhoea secondary to rapid intestinal transit. The latter may be treated by adding pectin to the feed or with loperamide. ${ }^{43}$

(4) ASSESSMENT OF SMALL BOWEL FUNCTION Intestinal permeability or absorption may be evaluated by urinary excretion of oral 51chromium EDTA; or D-xylose absorption. In practice, intestinal function is best evaluated by measuring the stoma output and assessing reducing substances and steatocrit. ${ }^{43}$

\section{Results of small bowe1/liver transplantation \\ SURVIVAL}

The first successful recipient of a combined liver and small bowel transplant has survived more than four years. ${ }^{44}$ The London, Ontario group have reported three deaths and one graft loss in eight adult intestinal recipients ${ }^{44}$ while the Omaha, Nebraska group report six out of seven children surviving combined liver and small bowel transplantation. One child lost her graft, the remaining children discontinued TPN within 13 weeks postoperatively. ${ }^{45}$

The greatest experience is from the University of Pittsburg where intestinal transplantation has been performed in 59 patients,
32 of whom were children (mean age $3 \cdot 8$ years). They performed isolated small bowel transplantation in 22, combined intestinal/liver grafts in 26, and multivisceral (liver, small bowel, stomach, and pancreas) transplants in 11 . One year patient survival in paediatric recipients was $75 \cdot 6 \%$ while graft survival was $68 \%$. $^{10}$

Two year survival figures for the whole group were $80 \%$ for isolated small bowel and $59 \%$ for combined grafts. ${ }^{46}$ There were 21 deaths in the whole group: two operative deaths, seven patients died of rejection, five of sepsis, four of lymphoproliferative disease, two from respiratory problems, and one of catheter related problems.

The major complications were bacterial, viral or fungal sepsis $(90 \%)$, acute rejection $(66 \%)$, lymphoproliferative disease $(6 \%$ of all patients and $11 \%$ of paediatric patients). Nine patients required intestinal retransplantation. ${ }^{1046}$

\section{QUALITY OF LIFE}

The main aim of intestinal transplantation is to restore intestinal function and normal quality of life. In the Pittsburg group, 31/39 survivors were totally free from TPN and were on normal oral diets, 5/39 required partial TPN, and one required total TPN. ${ }^{46}$

There are potential problems in establishing normal enteral feeding in children as many paediatric patients will have had no previous experience of normal feeding. Of 15 paediatric survivors in the Pittsburg programme six children were identified as having significant behavioural or functional problems requiring intensive intervention. Nine children eventually attained satisfactory eating habits with support but five still require supplemental enteral feeding. ${ }^{47}$

The median duration of hospitalisation was 80 days (range 33-319 days) ${ }^{31}$ but many patients have required readmission for treatment of rejection and opportunistic infection. ${ }^{37}$

\section{Demand for liver and bowel transplanta- tion in Britain}

The home TPN register held by Professor Miles Irving at Hope Hospital, Salford, estimates that approximately 50 adults and children at any one time are receiving long term TPN. ${ }^{14}$ Approximately $50 \%$ of this group will recover gut function and TPN will be discontinued. Of the remaining 25 patients 10 per year are likely to require small bowel transplantation. ${ }^{14}$ Based on our experience in children with intestinal failure in the West Midlands, we estimate 10 children in the UK will need this operation annually (Professor I W Booth, personal communication). To date we have assessed 17 children in Britain for this operation. ${ }^{27}$

\section{Conclusion}

Small bowel and/or liver transplantation is an established technique with clearly defined indications for which there is an appreciable 
demand in the UK. ${ }^{27}$ As experience with this technique grows it is likely that the indications for both combined and isolated small bowel transplantation will increase in the future.

It is clear that GVHD is uncommon in humans and that intestinal rejection may be controlled with FK506. Nevertheless before this technique becomes generally accepted, there are a number of unresolved issues. (1) There are particular difficulties in finding suitable donors for small children and unless there are major changes in our donor philosophy, many children will never be able to benefit from this technique, particularly, if referred late with advanced liver disease. (2) There are major problems with the management of immunosuppression of the transplanted gut, and the prevention and diagnosis of rejection. If this technique is to succeed long term it will be necessary to establish the correct balance between immunosuppression, infection, and rejection. (3) In children there may be particular problems with the development of normal feeding behaviour and their long term prognosis will be affected by the high risk of lymphoproliferative disease in those children who are negative for Epstein-Barr virus before transplantation.

Future programmes will not only need to answer these questions, but to prospectively evaluate the many social and psychological issues with reference to quality of life, long term graft function, and the prevention of lymphoproliferative disease. It will also be important to establish the cost effectiveness ratio of this treatment compared with currently funded health care intervention.

We feel that there is already a definite demand for small bowel transplantation in the UK in those patients who would otherwise die of intestinal failure and that there is now sufficient experience world wide for the technique to be properly evaluated and established in this country.

1 Mayer AD. Small bowel transplantation. In: Neuberger JA, Lucey M, eds. Balliere's clinical gastroenterology. London: Balliere Tindall, 1994; 8 (3)

2 Carrel A. La technique operitoire des anastomes vasculaires et la transplantation des visceres. Lyon Mediterranee Medical 1902; 98: 859-64.

3 Lillehei RC, Idezuki Y, Feemster JA, et al. Transplantation of stomach intestine and pancreas; experimental and clinical observations. Surgery 1967; 62: 721-41.

4 Starzl TE, Kaupp HA. Mass homotransplantation of abdominal organs in dogs. Surgical Forum 1960; 11: 28-30.

5 Deltz E, Schroeder P, Gundlach M, et al. Successful clinical small bowel transplantation. Transplant Proc 1990; 22: 501.

6 Starzl TE, Rowe MI, Todo S, et al. Transplantation of multi-abdominal viscera. $\mathscr{A} A M A$ 1989; 261: 1449-57.

7 Grant D, Wool W, Mimeaul TR, et al. Successful small bowel liver transplantation. Lancet 1990; 335: 181-4.

8 Starzl TE, Todo S, Tzakis A, et al. Multi visceral and intestinal transplantation. Transplant Proc 1992; 24: 1217-23.

9 Reyes J, Tzakis A, Todo S, et al. Candidates for small bowel transplantation and possible indicators of outcome. Transplant Proc 1994; 26: 1447.

10 Todo S, Tzakis A, Reyes J, et al. Clinical intestinal transplantation 3 year experience. Transplant Proc 1994; 26: 1409-10.

11 Abu-Elmagd, Todo S, Tzakis A, et al. Three years clinical experience with intestinal transplantation. fournal of the American College of Surgeons 1994; 179: 385-400.

12 Tzakis A, Todo S, Reyes J, et al. Evolution of surgical techniques in clinical intestinal transplantation. Transplant Proc 1994; 26: 1407-8.

13 Lennard-Jone JE. Indications and need for long term parenteral nutrition; implications for intestinal transplantation. Transplant Proc 1990; 22: 2427-9.

14 Moghal N, Irving $M$. Home parenteral nutrition in the United Kingdom and Ireland. Lancet 1986; ii: 383-7.
15 De-Potter S, Goulet O, Lamor M, et al. 263 patient years of home parenteral nutrition in children. Transplant Proc 1992; 24: 1056-7.

16 Puntis JWL, Holden CE, Snorman S, Finkel Y, George RH, Booth IW. Staff training: a key factor in reducing intravascular catheter sepsis. Arch Dis Child 1991; 66: 335-7.

17 Galaem H, Holliday H, Carachi $\mathrm{R}$, et al. Short bowel syndrome a collective review. I Pediatr Surg 1992; 27: 592-6.

18 Weber TR, Tracy T, Connors RH. Short bowel syndrome in children; quality of life in an era of improved survival. Arch Surg 1991; 126: 841-6.

19 Wesley JR. Efficacy and safety of total parenteral nutrition in paediatric patients. Mayo Clin Proc 1992; 67: 671-5.

20 Bisset WM, Stapleford P, Long S, et al. Home parenteral nutrition in chronic intestinal failure. Arch Dis Child 1992; 67: 109-14.

21 Burnes JU, O'Keefe SJ, Flemming CR, et al. Home parenteral nutrition. 3-year analysis of clinical and laboratory monitoring. Fournal of Parenteral and Enteral Nutrition 1992; 16: 327-32

22 Ricour C, Gorski AM, Goulet O, et al. Home parenteral nutrition in children. Eight years experience with 112 patients. Clinical Nutrition 1990; 9: 65-71.

23 Pollard AJ, Sreeram N, Wright JG, Beath SV, Booth IW, Kelly DA. Pulmonary embolism in children - another hazard of parenteral feeding. Gut 1994; 35: S33.

24 Ingham-Clarke C. Recent progress in intestinal transplantation. Arch Dis Child 1992; 67: 976-9.

25 Stera DM, Brett S, Harris K, et al. Participation of endothelial cells in the protein C-protein $S$ anticoagulant pathway;
the synthesis and release of protein S. $f$ Cell Biol 1986; the synthesis

26 Tzakis AJ, Todo S, Reyes J. Clinical intestinal transplantation; focus on complications. Transplant Proc 1992; 24: $1238-40$

27 Beath SV, McKiernan PJ, Murphy MS, et al. Paediatric referrals for combined small bowel and liver transplantation: timing and indications; room for improvement? Proc Nutr Soc 1994; 54: 2 .

28 Colom G, Goulet O, Reillon Y, et al. Cholestatic liver disease after small bowel transplantation failure in children. Transplant Proc 1994; 26: 1429-30.

29 Todo S, Tzakis A, Abu-Elmagd K, et al. Intestinal transplantation in composite visceral grafts or alone. Ann Surg 1992; 216: 223-34.

30 Tzakis AG, Todo S, Reyes J, et al. Piggy back orthotopic intestinal transplantation. Surg Gynecol Obstet 1993; 176: 297-8.

31 Funovits M, Millar SR, Kovalak J, et al. Hospitalisation and readmission of intestinal transplantation recipients. Transplant Proc 1994; 26: 1419-20.

32 Iwaki Y, Starzl TE, Yagihashi A, et al. Replacement of donor lymphoid tissue in small bowel transplants. Lancet 1991; 337: 818-9.

33 Grant DR. Immunosuppression for small bowel transplantation. Clinical Transplantation 1991; 5: 563-7.

34 Hoffman AL, Makowska L, Banner B, et al. Use of FK506 for small intestinal transplantation. Transplantation 1990; 49: 483-90.

35 Abu-Elmagd K, Tzakis A, Todo S. Monitoring and treatment of rejection in humans. Transplantation 1993; 25: 1202-3.

36 Goulet O, Brousse N, Revillon Y, Ricour C. Pathology of human intestinal transplantation. In: Grant DR, Wood hF, eds. Small bowel transplantation. London: Edward RF, eds. Small bowel

37 Green M, Reyes J, Nour B, et al. Early infectious complications of liver intestinal transplantation in children. Transplant Proc 1994; 26: 1420-1.

38 Bonet H, Reyes J, Tzakis A, et al. Lymphoproliferative disease after combined liver and small bowel transplantation. Transplant Proc 1994; 26: 1426-7.

39 Cox K, Lawrence L, Garcia Kennedy R, et al. Increased incidence of EBV infection and lymphoproliferative disease (LPD) in young children on FK506 after liver transplantation. Transplant Proc 1995 (in press).

40 Lear PA. The physiology of transplanted small intestine. In: Grant DR, Wood RFM, eds. Small bowel transplantation. London: Edward Arnold, 1994: 18-29.

41 Mainous M, Dazhong X, Qil B, Berg RD, Deitch EA. Oral TPN induced bacterial translocation and impaired immune defences are reversed by refeeding. Surgery 1991; 110: 277-84.

42 Maynard ND, Bihari DJ. Post operative feeding. BMF 1991; 303: 1007-8

43 Beath SV, Kelly DA, Booth IW, et al. Post operative care of children undergoing combined small bowel and liver transplantation. British fournal of Intensive Care 1994; 4: 302-8.

44 Grant DR, Wall W, Ghent C, et al. Small bowel transplantation at University Hospital London Ontaria Canada. Transplant Proc 1994; 26: 1430-1.

45 Langnas A, Vanderhoof JA, Antonson DL, et al. Human intestinal transplantation and effective treatment of intestinal failure. Transplant Proc 1995; (in press).

46 Todo S, Tzakis A, Reyes J. et al. Intestinal transplantation in humans - four year experience. Transplant Proc 1995; (in press).

47 Staschak-Chicko S, Altieri D, Funovits $M$, et al. Eating difficulties in the paediatric small bowel recipient. Transplant Proc 1994; 26: 1434-5. 